\section{revisão}

\section{Regina do Carmo Silva}

Margaret de Castro

Claudio E. Kater

Andréa Aparecida Cunba

Andréia M. de Moraes

Daniela B. de Alvarenga

Ayrton C. Moreiva

Lucila L.K. Elias

\title{
Insuficiência Adrenal Primária no Adulto: 150 Anos Depois de Addison
}

\section{RESUMO}

Thomas Addison descreveu pela primeira vez, há 150 anos, uma síndrome clínica de perda de sal em indivíduos com hiperpigmentação cutânea, associada à destruição da glândula adrenal. Atualmente, a insuficiência adrenal ainda representa uma condição de risco, pois seu diagnóstico é freqüentemente não reconhecido nas fases iniciais da doença. A adrenalite tuberculosa era a causa mais freqüente na maioria dos casos descritos inicialmente, mas, na atualidade, a doença de Addison auto-imune está presente em uma grande porcentagem de pacientes com insuficiência adrenal primária. No presente trabalho, apresentamos a prevalência das diferentes causas, manifestações clínicas e achados laboratoriais, incluindo a determinação de anticorpos anticórtex adrenal e anti-21-hidroxilase em pacientes acompanhados com insuficiência adrenal primária seguidos nos Ambulatórios das Divisões de Endocrinologia da Universidade Federal de São Paulo (UNIFESP) e da Faculdade de Medicina de Ribeirão Preto - USP (FMRP-USP). (Arq Bras Endocrinol Metab 2004;48/5:724-738)

Descritores: Insuficiência adrenal; Doença de Addison; Adrenalite autoimune; Anticorpos anti-adrenal; Anticorpos anti-21-hidroxilase; Tuberculose

\begin{abstract}
Primary Adrenal Insufficiency in Adults: 150 Years After Addison. Thomas Addison first described, 150 years ago, a clinical syndrome characterized by salt-wasting and skin hyperpigmentation, associated with a destruction of the adrenal gland. Even today, over a century after Addison's report, primary adrenal insufficiency can present as a lifethreatening condition, since it frequently goes unrecognized in its early stages. In the 1850's, tuberculous adrenalitis was present in the majority of patients, but nowadays, autoimmune Addison's disease is the most common cause of primary adrenal insufficiency. In the present report, we show the prevalence of different etiologies, clinical manifestations and laboratorial findings, including the adrenal cortex autoantibody, and 21-hydroxylase antibody in a Brazilian series of patients with primary adrenal insufficiency followed at Divisão de Endocrinologia da Universidade Federal de São Paulo (UNIFESP) and at Faculdade de Medicina de Ribeirão Preto - USP (FMRP-USP). (Arq Bras Endocrinol Metab 2004;48/5:724-738)
\end{abstract}

Keywords: Adrenal insufficiency; Addison's disease; Autoimmune adrenalitis; Anti-adrenal auto-antibodies; Anti-21-hydroxylase auto-antibodies; Tuberculosis 


\section{HISTÓRICO}

A GLÂNDULAS SUPRA-RENAIS FORAM descritas pelo anatomista Bartolomeo Eustachius em 1552 como "Glandulae renis incumbentes" no livro Opuscula Anatomica, sem oferecer uma explicação para a sua função. No século seguinte, a existência das supra-renais foi mencionada por outros anatomistas. Em 1627, Adrianus Spigelius usou o termo "capsulae renales" e, segundo ele, elas serviriam para ocupar o espaço entre os rins e o diafragma. Nathaniel Highmore sugeriu que as adrenais absorveriam os exsudatos dos grandes vasos vizinhos. Jean Riolan, o Velho, em 1611, pensou que as supra-renais manteriam um grupo de nervos acima dos rins, no que foi refutado por Antonio Molinetti em 1675. Caspar Bartholinus foi o primeiro a acreditar que existia um humor, o qual chamou "atrabilia" (do latim atrabilis bílis negra ou humor imaginário que se julgava a causa da melancolia), que era contido na cavidade das adrenais e passava por canais aos rins e à urina. Jean Riolan, o Jovem, descreveu que as adrenais do feto eram maiores do que na vida pós-natal e concluiu que elas eram ativas somente na vida fetal. Em 1707, Pierre Dionis disse que as adrenais funcionariam como rins durante a vida fetal.

Em 1716, a Academia de Ciências de Bordeaux ofereceu um prêmio sobre o tema "Quel est l'usage des glandes surrénales?". Nenhum ensaio foi considerado suficientemente convincente para receber o prêmio. Esta decisão foi divulgada em 1718 pelo Secretário da Academia, o filósofo Charles de Montesquieu, com as palavras: "Talvez um dia o acaso poderá trazer o que estes trabalhos deixaram de fazer".

Após 3 séculos de especulação desde a sua descrição anatômica, a primeira grande contribuição sobre o papel funcional das adrenais veio em 1855 com Thomas Addison (1), que descreveu em 11 pacientes o quadro clínico da insuficiência adrenal primária, correlacionando-o com achados de autópsia. As palavras do próprio Addison refletiam o espírito científico do médico: "Após lógica inferência e a observação de fatos concorrentes, pronunciava com considerável confiança a existência de doença das cápsulas supra-renais". Este marco da moderna endocrinologia foi seguido, em 1856, pelo estudo experimental de Charles Brown - Séquard, que realizou adrenalectomia em várias espécies de animais e concluiu que as adrenais eram "órgãos essenciais à vida".

$\mathrm{Na}$ segunda metade do século 19 , foi iniciado o período da opoterapia. Adrenais bovinas grelhadas e depois extratos glicéricos de adrenais suínas eram administrados tanto aos pacientes com doença de Addison como aos animais adrenalectomizados (Oliver e Schaefer, 1893; Cybulski e Szymonowicz, 1895; Osler, 1896). Apesar da melhora temporária dos pacientes, desconhecia-se a natureza dos princípios ativos secretados pelas adrenais.

$\mathrm{O}$ isolamento da adrenalina da medula adrenal por Takamine e Aldrich em 1901 e a demonstração da sua ineficácia no tratamento da doença de Addison, indicavam que as substâncias essenciais à vida eram produzidas pelo córtex-adrenal. Os primeiros extratos cristalinos dos esteróides corticais foram obtidos em 1933 independentemente por Kendall e Grollman. Em 1938, Reichstein isolou e identificou um esteróide que foi chamado corticosterona (ou composto B de Kendall). Em 1937, Steiger e Reichstein anunciaram a síntese do primeiro esteróide adrenal, o acetato de desoxicorticosterona (DOCA). Este esteróide usado no tratamento da doença de Addison mostrou maior atividade na retenção de sódio e água do que na correção da hipoglicemia. No período de 1943 a 1946, Reichstein, Kendall e Sarett conseguiram sintetizar a cortisona e a hidrocortisona. Em 1949, a cortisona foi usada na terapia da doença de Addison. Entre 1952 a 1954, foi purificada e isolada a aldosterona (Simpson e Tait).

A existência de um fator hipofisário controlando as adrenais foi aventada em 1927 por Philip Smith em ratos hipofisectomizados. Posteriormente, foram obtidos extratos hipofisários com atividade estimulante adrenocortical, culminando com o isolamento da estrutura química do ACTH (Li, Simpson e Evan, 1943). Na década de 40, surgiram os primeiros testes laboratoriais para o diagnóstico da insuficiência adrenal: a determinação colorimétrica dos 17 cetoesteróides e corticosteróides urinários basais e o teste da reserva adrenal com ACTH, usando, no início, a contagem de eosinófilos (teste de Thorn) ou a determinação do 17 cetoesteróides e, subseqüentemente, as dosagens de 17 hidroxicorticosteróides urinários ou o cortisol plasmático. Nos anos 50, bioensaios para o ACTH usando ratos hipofisectomizados mostraram os elevados níveis de ACTH plasmáticos na doença de Addison, o que foi confirmado em 1968-1972 pelos radioimunoensaios do ACTH. Em 1955, os grupos de Schally e Guillemin demonstraram que extratos hipotalâmicos liberavam ACTH e finalmente, em 1981, Wylie Vale e colaboradores caracterizaram a estrutura do $\mathrm{CRH}$ (hormônio liberador da corticotrofina).

Nas duas últimas décadas, o avanço tecnológico permitiu um melhor conhecimento da genética, etiopatogênese, história natural e tratamento da doença de Addison. Ainda, houve maior disponibili- 
dade dos imunoensaios do ACTH e cortisol e de outros esteróides, facilitando o diagnóstico desta e de outras doenças adrenais.

Os dados históricos referidos podem ser encontrados nas referências 1,2 e 3 .

\section{PREVALÊNCIA E ETIOLOGIA}

A doença de Addison (DA) é relativamente rara, com prevalência entre 0,45 a 11,7 casos por 100.000 habitantes (4-8). No entanto, atualmente, a prevalência da DA na população geral é três vezes maior que a observada na década de 70 , sendo que a doença é clinicamente evidente em aproximadamente 1 em cada 8000 indivíduos nos países europeus. Ainda não se sabe se essa maior prevalência é conseqüência da maior acurácia diagnóstica ou se reflete, realmente, uma freqüência mais alta da insuficiência adrenal primária clínica $(9)$.

Nos adultos, a DA pode ser causada pela destruição auto-imune das células do córtex adrenal, a qual pode se apresentar de forma isolada ou estar associada a outras endocrinopatias, caracterizando síndromes poliglandulares auto-imunes (SPAs) dos tipos 2 e 4 (10). A DA também pode ser secundária à infecção tuberculosa, fúngica ou viral, infiltração por neoplasias primárias ou metastáticas, hemorragia ou trombose adrenal, amiloidose, sarcoidose, hemocromatose, ou estar relacionada ao uso de drogas que interferem com a esteroidogênese adrenal. Essas etiologias são mais comuns com o avanço da idade, tanto em homens como em mulheres (11). As hiperplasias adrenais congênitas, insensibilidade ao ACTH, hipoplasia adrenal congênita, deleções do DNA mitocondrial e os defeitos da biossíntese do colesterol são causas genéticas de DA e se manifestam desde o nascimento até a adolescência e serão objetos de outra revisão nesta mesma edição. A adrenoleucodistrofia e a adrenomieloneuropatia são causas raras de DA, de origem genética, que podem ocorrer, também, em homens adultos e em mulheres adultas heterozigotas (11-13).

Após a introdução de terapia anti-tuberculosa eficaz, a auto-imunidade tornou-se a principal causa de DA, sendo responsável por 68 a $94 \%$ dos casos $(5,9,14)$ de acordo com os relatos da literatura americana e européia. No entanto, a adrenalite de causa granulomatosa (pós-tuberculose e paracoccidioidomicose) ainda é bastante freqüente em vários países (9). A tabela 1 apresenta a etiologia da insuficiência adrenal primária em uma série de 82 pacientes acompanhados na Divisão de Endocrinologia da Universidade Federal de São Paulo (UNIFESP) e da Faculdade de Medicina de Ribeirão Preto - USP (FMRP-USP). Podemos observar que, em média, a etiologia autoimune esteve presente em 39\% dos casos, seguida de paracoccidioidomicose (28\%) e tuberculose (11\%). Analisando estes resultados, observamos diferentes prevalências quanto à etiologia nos dois centros. $\mathrm{Na}$ UNIFESP, predomina a etiologia auto-imune $(52,6 \%)$, semelhante ao observado nas casuísticas da literatura mundial. Contudo, a maior ocorrência de DA secundária à paracoccidioidomicose foi relativamente freqüente na casuística de Ribeirão Preto, pois este centro está localizado em uma região endêmica de paracoccidioidomicose e, adicionalmente, neste centro a divisão de Moléstias Infecciosas é referência em pesquisa e assistência desta doença.

\section{DOENÇA DE ADDISON AUTO-IMUNE}

Várias evidências indicam um papel da auto-imunidade na patogênese da DA, entre elas, os modelos experimentais, a presença de adrenalite no exame histopa-

Tabela 1. Distribuição por idade, sexo e etiologia em 82 pacientes com insuficiência adrenal primária (UNIFESP e FMRP-USP).

\begin{tabular}{lccc}
\hline & $\begin{array}{c}\text { UNIFESP } \\
\text { (N: 38) }\end{array}$ & $\begin{array}{c}\text { FMRP-USP } \\
\text { (N: 44) }\end{array}$ & $\begin{array}{c}\text { Total } \\
\text { (N: 82) }\end{array}$ \\
\hline Sexo & $21 \mathrm{M}, 17 \mathrm{~F}$ & $32 \mathrm{M}, 12 \mathrm{~F}$ & $53 \mathrm{M}, 29 \mathrm{~F}$ \\
$\begin{array}{lccc}\text { Idade ao diagnóstico } \\
\text { (mediana) }\end{array}$ & 43,5 anos & 37 anos & \\
Etiologia Auto-imune & $52,6 \%$ & $25 \%$ & $39 \%$ \\
Paracoccidioidomicose & $18,4 \%$ & $36,4 \%$ & $28 \%$ \\
Tuberculose & $15,8 \%$ & $6,8 \%$ & $11 \%$ \\
Adrenoleucodistrofia & & $13,6 \%$ & $7,3 \%$ \\
Outras causas (Metástase, & & & \\
hemorragia, citomegalovírus) & $7,9 \%$ & $6,8 \%$ & $4,9 \%$ \\
Sem causa determinada & $5,3 \%$ & $11,4 \%$ & $10,9 \%$ \\
\hline
\end{tabular}


tológico, as alterações da imunidade mediada por células, a associação com outras doenças auto-imunes e com marcadores imunogenéticos e a presença de autoanticorpos circulantes. Adrenalite auto-imune tem sido induzida em animais por meio de injeção de homogenados de adrenal autólogos ou heterólogos misturados a vários adjuvantes. A repetição da imunização causa uma hipersensibilidade do tipo tardio aos antígenos adrenais. Não é possível a transferência passiva da adrenalite de um animal afetado para um saudável pelo soro. Em alguns experimentos, a doença foi transferida por meio de linfonodos ou esplenócitos, mas insuficiência adrenocortical não se desenvolveu, sugerindo que a imunidade mediada por células seja crítica para a patogênese da adrenalite auto-imune experimental $(10,15)$. Timectomia no terceiro dia de vida, após o tratamento neonatal com ciclosporina, altera o balanço entre células $\mathrm{T}$ autoreativas e células $\mathrm{T}$ reguladoras, com predomínio do primeiro tipo de células, podendo levar ao aparecimento de ooforite ou orquite, tireoidite, gastrite e adrenalite $(10,16)$.

No que se refere aos achados histopatológicos, as adrenais de pacientes com DA auto-imune são atróficas. Na fase ativa da doença, observa-se presença de infiltrado celular mononuclear, constituído de linfócitos, plasmócitos e macrófagos, assim como perda da arquitetura normal do córtex. As células adrenocorticais apresentam necrose e pleomorfismo. Com a progressão da doença, os nódulos corticais residuais são destruídos e substituídos por tecido fibroso. No estágio final, os únicos componentes celulares normais remanescentes nas adrenais são as células da medula $(17,18)$. Estudos recentes sobre a natureza do infiltrado linfócitário presente no córtex adrenal demonstraram predomínio de linfócitos $\mathrm{T}$ CD4+, a maioria deles ativado, com co-expressão do receptor para interleucina-2. Linfócitos T CD8+e células B CD22+ também estão presentes, mas em menor número (19).

Em relação à imunidade celular, foi demonstrado que $46 \%$ a $60 \%$ dos pacientes com DA auto-imune apresentam menor capacidade de migração de macrófagos na presença de antígenos adrenais (20). Além disso, uma redução inespecífica da função dos linfócitos $\mathrm{T}$ e um aumento da porcentagem de linfócitos $\mathrm{T}$ ativados circulantes, em pacientes com menos de um ano de duração da doença, também foram descritos $(21,22)$. Finalmente, uma resposta proliferativa da célula $\mathrm{T}$ a proteínas adrenais com peso molecular de 18 a $24 \mathrm{KDa}$ foi demonstrada em $60 \%$ dos pacientes com DA auto-imune (23).

\section{SÍNDROMES POLIGLANDULARES AUTO- IMUNES}

Cerca de $40 \%$ dos pacientes com DA auto-imune apresentam outras doenças auto-imunes associadas. Estas, em ordem de freqüência, são: tireoidite de Hashimoto (3,7-32\%), doença de Graves (2-22,7\%), gastrite crônica atrófica (25\%), diabetes mellitus tipo 1 (1,2-20,4\%), hipoparatireoidismo (1,2-20\%), hipogonadismo hipergonadotrófico (4,5-17,6\%), vitiligo $(0,8-16 \%)$, alopécia $(0,8-12 \%)$, doença celíaca $(1,2-8 \%)$, anemia perniciosa $(0,8-6 \%)$, esclerose múltipla $(3,7 \%)$, doenças inflamatórias intestinais $(2,4 \%)$, síndrome de Sjögren $(2,4 \%)$, hepatite crônica (1,6-3\%) e hipofisite linfocítica $(0,8 \%)$. Além disso, 4 a $17 \%$ dos pacientes com DA auto-imune isolada apresentam evidência de auto-imunidade contra outros órgãos, sendo positivos para um ou mais auto-anticorpos órgão específicos não adrenais (10). Na série de pacientes com insuficiência adrenal primária, acompanhados em nossos ambulatórios (UNIFESP e FMRP-USP), a doença de Addison auto-imune esteve freqüentemente associada com outras doenças autoimunes, sendo a grande maioria doença tireoidiana auto-imune, como Tireoidite de Hashimoto (56,7\%) ou doença de Graves (10\%), seguida de hipogonadismo hipergonadotrófico $(10 \%)$, diabetes mellitus tipo $1(6,7 \%)$ e gastrite atrófica $(6,7 \%)$.

\section{Síndrome Poliglandular Auto-Imune Tipo 2}

A SPA tipo 2 apresenta prevalência de $1,4-2,0$ por 100.000 habitantes. Afeta mais freqüentemente mulheres de meia idade (entre 20 e 40 anos) e se caracteriza pela presença de DA auto-imune (100\% dos casos) em associação com doenças tireoideanas auto-imunes (69-82\%, síndrome de Schmidt) e/ou diabetes mellitus tipo 1 (30-52\%, síndrome de Carpenter) $(10,24,25)$. O diabetes mellitus tipo 1 (DMl) e a doença de Graves geralmente se manifestam antes da DA e a tireoidite de Hashimoto aparece simultaneamente ou após o início da DA (24).

A SPA tipo 2 pode ser incompleta e subclínica quando houver presença de uma doença clínica característica da síndrome, com um ou mais marcadores sorológicos de outros componentes e alteração subclínica da função do órgão-alvo. Pacientes que apresentam uma doença auto-imune clínica e marcadores sorológicos de outra doença que compõe SPA tipo 2, mas com função normal dos órgãos-alvo, são portadores de SPA do tipo 2 incompleta e potencial (10).

Além dos componentes principais, outras doenças auto-imunes também podem estar presentes 
Tabela 2. Síndromes poliglandulares auto-imunes (SPA).

\begin{tabular}{ll}
\hline SPA & COMPONENTES \\
\hline TIPO 1 & $\begin{array}{l}\text { Candidíase crônica, hipoparatireoidismo, DA } \\
\text { (pelo menos dois presentes) } \\
\text { DA + doença tireoideana auto-imune e/ou } \\
\text { diabetes mellitus do tipo 1 (DA deve estar } \\
\text { sempre presente) } \\
\text { Doença tireoideana auto-imune + outra } \\
\text { doença auto-imune (excluindo DA, } \\
\text { hipoparatireoidismo e candidíase) } \\
\text { Duas ou mais doenças auto-imunes órgão- } \\
\text { específicas, incluindo DA (mas que não se } \\
\text { incluem nas síndromes dos tipos 1, 2 ou 3) }\end{array}$ \\
\hline
\end{tabular}

nesta síndrome, entre elas hipogonadismo hipergonadotrófico $(4-9 \%)$, vitiligo $(4,5-11 \%)$, alopécia (1-4\%), hepatite crônica (4\%), gastrite crônica atrófica com ou sem anemia perniciosa (4,5-11\%) e hipofisite (10).

A SPA tipo 2 geralmente ocorre em várias gerações da mesma família, sendo herdada de forma autossômica dominante, com penetrância incompleta (23). Embora seja poligênica, o principal fator genético responsável pela disfunção imunológica está localizado no cromossomo 6, na região do sistema HLA de classe II, o qual desempenha um papel chave na determinação das respostas das células T aos antígenos (16). Vários estudos confirmaram a associação da DA (como parte da SPA do tipo 2) com vários alelos dentro do haplotipo HLA-DR3, incluindo DRB1*0301, DQA1 *0501 e DQBI*0201 (DQ2). O haplotipo HLA-DR4 DQB1*0302 está aumentado nos pacientes com DA e DMl e o alelo HLA-DR5 naqueles com DA e doenças tireoideanas auto-imunes (2628). Outros genes dentro do complexo HLA também foram estudados, tais como o gene do fator de necrose tumoral, o gene ativo e o pseudogene da 21-hidroxilase (classe III do HLA), o HLA-B8 (classe I do HLA) e o gene relacionado à cadeia de classe I, localizado centromericamente ao gene do HLA-B (MIC-A5.1), os quais estão sempre associados aos determinantes de risco da classe II (10,29-31). Polimorfismos do gene CTLA-4 (cromossomo 2q33), que é um importante regulador negativo para a ativação das células $\mathrm{T}$, também podem estar significantemente associados com a DA, no subgrupo de pacientes portadores do alelo HLA-DQAl *0501 $(32,33)$.

\section{Síndrome Poliglandular Auto-Imune Tipo 4}

A SPA tipo 4 é uma síndrome rara, caracterizada pela associação de doenças auto-imunes não incluídas nas outras categorias de SPAs, como por exemplo: DA associada a um ou mais componentes menores (hipogonadismo, gastrite crônica atrófica, anemia perniciosa, doença celíaca, miastenia gravis, vitiligo, alopécia, hipofisite etc.), mas excluindo-se os componentes maiores característicos das SPAs tipo 1 e 2 (candidíase mucocutânea crônica, hipoparatireoidismo, doenças auto-imunes tireoideanas e DMl) (10).

\section{Auto-Anticorpos Circulantes}

Em 1957, Anderson e cols. demonstraram pela primeira vez a presença de auto-anticorpos anticórtex adrenal (ACA) no soro de portadores de adrenalite auto-imune (34). Os ACA são imunoglobulinas das subclasses IgGl, IgG2 e IgG4, detectadas por imunofluorescência indireta (ACA-IFI) ou pela técnica da proteína A-imunoperoxidase (ACA-PAIP) em cortes criostáticos de adrenal humana ou bovina. Estes anticorpos são encontrados em $60 \%$ a $81 \%$ dos pacientes com DA de etiologia auto-imune $(10,35,36)$ e são órgão-específicos, reagindo com as três camadas do córtex adrenal, produzindo um padrão de coloração homogênea do citoplasma (figura 1).

De acordo com a casuística da Disciplina de Endocrinologia - UNIFESP, os ACA-IFI e os ACAPAIP estão presentes em 77\% e 69\% dos casos de DA clinicamente idiopática, respectivamente. A concordância de $60 \%$ entre as duas metodologias e o fato de $92 \%$ dos pacientes serem positivos para ACA-IFI e/ou ACA-PAIP, sugerem que essas duas técnicas devam ser complementares para a detecção de ACA no soro humano (36).

Auto-anticorpos reativos contra a superfície da célula adrenocortical foram demonstrados em $86 \%$ dos pacientes com DA idiopática positivos para ACA, sugerindo que eles possam desempenhar um papel relevante na patogênese da DA auto-imune. Estes anticorpos podem exercer efeito citotóxico direto sobre as

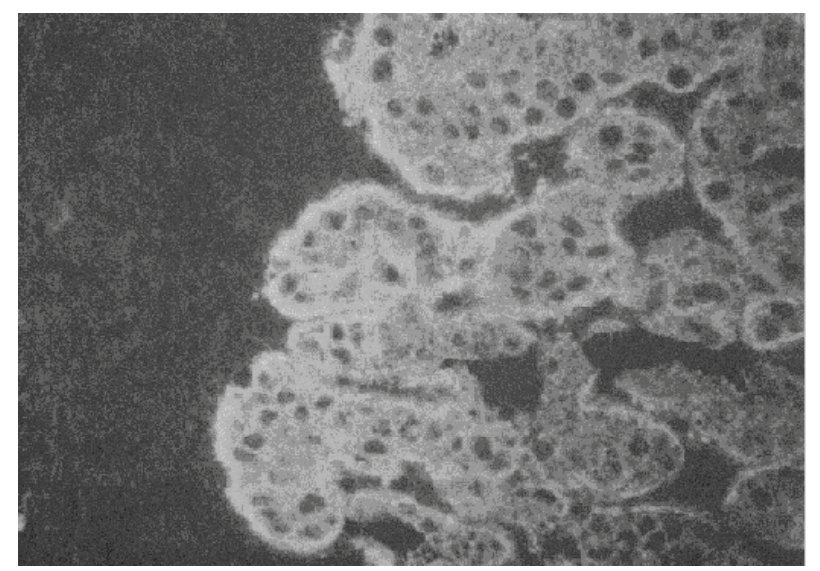

Figura 1. Auto-anticorpos anticórtex adrenal detectados por imunofluorescência indireta (ACA-IFI). 
células adrenais, por meio de opsonização, fixação do complemento e ativação dos monócitos ou células "natural killer" (37). Em 1992, a identificação da enzima esteroidogênica 21-hidroxilase $(21 \mathrm{OH})$ como o principal auto-antígeno reconhecido pelos ACA, tanto na DA auto-imune isolada como naquela associada à SPA tipo 2 (38), permitiu o desenvolvimento de radioensaios altamente sensíveis e específicos para a detecção de auto-anticorpos anti-210H (210HAc) $(39,40)$. Estes anticorpos estão presentes em $64 \%$ a $89 \%$ dos casos de DA auto-imune (39-41) e em $85 \%$ a $96 \%$ dos casos de SPA tipo 2 (16). A prevalência de ACA-IFI e de 21 OHAc é tanto maior quanto menor a duração da DA $(9)$.

Em estudo realizado pela Disciplina de Endocrinologia - UNIFESP em colaboração com a Universidade de Perugia, Itália, pudemos observar a presença de ACA-IFI e 210 HAc, respectivamente, em $83 \%$ e $78 \%$ dos pacientes com DA idiopática, sendo que 94\% desses pacientes foram positivos para ACA e/ou $210 H A c$. Isto sugere que a determinação desses autoanticorpos deva ser o primeiro passo na investigação da etiologia auto-imune em pacientes com DA $(9,40)$. Os títulos de ACA-IFI se correlacionaram positivamente com os de 210 HAc e os resultados de ambas as metodologias foram concordantes em $83 \%$ dos casos. Apenas um único paciente (9\%) com DA de origem granulomatosa apresentou resultado positivo para ambos os auto-anticorpos (40).

De acordo com Falorni e cols. (9), a presença simultânea de ambos os anticorpos (ACA-IFI e 21OHAc) é o melhor parâmetro para o diagnóstico da DA de etiologia auto-imune. A presença de apenas um deles, principalmente se em baixos títulos, não exclui, necessariamente, a origem não auto-imune da $\mathrm{DA}$, uma vez que eles podem ser esporadicamente detectados em pacientes com adrenalite pós-tuberculose, como citado anteriormente $(9,40)$. Isso pode resultar da coexistência dos dois processos num mesmo indivíduo ou ser secundário à liberação de antígenos adrenais, ocasionada pela destruição inflamatória do córtex adrenal, com subseqüente produção de anticorpos em indivíduo geneticamente predisposto $(9,40)$. Também não pode ser excluída a presença de resultados falso-positivos dos ensaios para os auto-anticorpos (9). A reatividade dos 210HAc existentes no soro de pacientes com diferentes formas de DA auto-imune (isolada ou associada às SPAs, subclínica ou potencial) é limitada às regiões média e carboxi-terminal da proteína, as quais interagem para formar um epítopo conformacional (tridimensional) muito conservado (4246). A seqüência de aminoácidos da região carboxi- terminal da molécula da $210 \mathrm{H}$ interage com o grupo heme enquanto a porção central da proteína forma $o$ sítio de ligação esteróide, sendo, portanto, importantes para a atividade enzimática (45).

Alguns pacientes com DA têm auto-anticorpos reativos não só contra as células adrenocorticais, mas também contra outras células produtoras de esteróides, tais como as células de Leydig dos testículos, as células da teca dos ovários e os sinciciotrofoblastos da placenta. Estes auto-anticorpos, denominados anti-células produtoras de esteróides (ACPE), são reativos contra as enzimas esteroidogênicas $17 \delta$ hidroxilase (17OH) e colesterol desmolase (SCC), sendo marcadores de falência ovariana precoce (10,40,47-53). Os ACPE também podem ser reativos contra a 3ß-hidroxiesteróide desidrogenase (54) e uma proteína de $51 \mathrm{KDa}$ de função desconhecida, localizada no retículo endoplasmático das células da granulosa e placenta $(55)$.

No referido estudo em colaboração com a Universidade de Perugia, Itália, detectamos anticorpos anti-SCC (SCCAc) e anti-17OH (17OHAc), em respectivamente $28 \%$ e $11 \%$ dos pacientes com DA idiopática (40). Portanto, dada sua baixa prevalência na DA auto-imune isolada e naquela associada à SPA tipo 2, a dosagem desses anticorpos só deve ser indicada nos casos onde os 210 HAc são negativos e/ou especialmente nas pacientes com falência ovariana precoce, mas não exclusivamente nos pacientes positivos para ACA-IFI. De acordo com Seissler e cols. (56), a presença de $17 \mathrm{OHAc}$ e SCCAc indica a coexistência e/ou progressão para auto-imunidade poliglandular.

As três principais enzimas reconhecidas como antígenos-alvo na DA auto-imune são membros da família de enzimas citocromos $\mathrm{P} 450$, localizadas no retículo endoplasmático $(210 \mathrm{OH}$ e $17 \mathrm{OH})$ ou na mitocôndria (SCC) das células do córtex adrenal, as quais estão envolvidas com a síntese dos principais hormônios esteróides derivados do colesterol: cortisol, aldosterona, dehidroepiandrosterona e androstenediona. A $210 H$ é específica do córtex adrenal, a $170 H$ é expressa na adrenal e gônadas e a SCC está presente nas adrenais, gônadas e placenta (10). A existência de auto-anticorpos bloqueadores do receptor do ACTH ainda não está bem estabelecida (57-59).

\section{PATOGÊNESE DA DOENÇA DE ADDISON AUTO-IMUNE}

A atuação de fatores desencadeantes ambientais (infecções virais, drogas, tabagismo, alimentos ou 
estresse) em indivíduos geneticamente predispostos resulta em quebra da tolerância imunológica. A persistência de clones de linfócitos T auto-reativos (que normalmente seriam deletados) somada a uma deficiência de subpopulações de células T reguladoras permite o aparecimento da auto-imunidade anti-adrenal (16). A apresentação de auto-antígenos adrenocorticais por células apresentadoras de antígenos (macrófagos, células dendríticas e linfócitos B) aos linfócitos Thelper (Th0) CD4+ auto-reativos, em associação com moléculas do HLA de classe I ou II e outras moléculas co-estimulatórias, é o primeiro passo para o início da doença (16). A expressão aberrante de antígenos do HLA de classe II pelas células do córtex adrenal, decorrente do estímulo inespecífico do interferon $\delta$, liberado pelo infiltrado inflamatório, também permite à célula adrenal apresentar auto-antígenos aos linfócitos T (60).

$\mathrm{A}$ ativação de células $\mathrm{T}$ belper (Th0) antígenoespecíficas leva à produção de interleucina-2 e outras linfocinas, as quais induzem tanto a ativação de linfócitos $\mathrm{T}$ citotóxicos (Thl) como de linfócitos Th2, os quais estimulam os linfócitos $\mathrm{B}$ a secretarem ACA/21OHAc específicos. Durante a resposta Thl, também ocorre ativação de fagócitos mononucleares, pois as citocinas Thl compreendem mediadores pró-inflamatórios. O dano resultante da liberação local de citocinas pelas células $\mathrm{T}$ do infiltrado, além da geração de radicais livres de oxigênio, parece ser a causa mais provável da perpetuação da destruição do córtex adrenal $(10,16)$.

O papel dos 210HAc na patogênese da DA auto-imune ainda não foi estabelecido in vivo. Parece que a destruição das células adrenocorticais mediada pelos linfócitos $\mathrm{T}$ é predominante, e a produção de $210 H A c$ é secundária à liberação de $210 H$ e peptídeos a ela relacionados. Assim, os 210HAc funcionariam apenas como marcadores sorológicos do processo auto-imune, apesar de se ligarem a sítios importantes para a atividade enzimática (61). Segundo Laureti e cols. (62), entretanto, a produção de $210 \mathrm{HAc}$ não é exclusivamente dependente da liberação de autoantígenos intracelulares, mas é resultado de um processo seletivo, oligoclonal e epítopo-específico, capaz de gerar anticorpos de alta afinidade pelo antígeno.

\section{HISTÓRIA NATURAL DA DOENÇA DE ADDISON AUTO-IMUNE}

A DA é uma doença crônica com um longo período pré-clínico silencioso. Três fases principais podem ser identificadas no curso da história natural da doença: 1) potencial, 2) latente ou subclínica, e 3 ) clínica (10) (figura 2). A fase potencial (estágio 0 ) é caracterizada pela presença de suscetibilidade genética e/ou presença de ACA e/ou 21OHAc, na ausência de qualquer alteração detectável da função adrenocortical. Desta forma, os 210HAc podem ser utilizados para discriminar indivíduos com processo auto-imune adrenal em desenvolvimento, assim como para detectar indivíduos de alto risco para o desenvolvimento da DA autoimune $(9,10)$. Esses auto-anticorpos estão presentes em 0,6 a $2,3 \%$ dos portadores de DMl, em 3\% daqueles com doença de Graves e em $2 \%$ daqueles com tireoidite de Hashimoto (63-65). Aproximadamente $21 \%$ a $50 \%$ dos pacientes com endocrinopatias autoimunes e 21OHAc positivos progridem para insuficiência adrenal clínica, após um período médio de latência de três anos $(66,67)$.

$\mathrm{Na}$ fase seguinte, disfunção adrenocortical pode se desenvolver após uma seqüência típica de três estágios disfuncionais subclínicos (estágios 1-3), o primeiro afetando a zona glomerulosa e, seqüencialmente, a zona fasciculada $(10,68)$. No estágio 1 , a primeira evidência bioquímica de falência adrenal subclínica é indicada pelo aumento da atividade plasmática da renina, na presença de níveis normais ou baixos de aldosterona, sugerindo que a zona glomerulosa é inicialmente afetada ou pode ser mais sensível à agressão auto-imune. Da mesma forma, a zona fasciculada pode ser protegida do ataque linfocitário por um período mais longo devido às altas concentrações

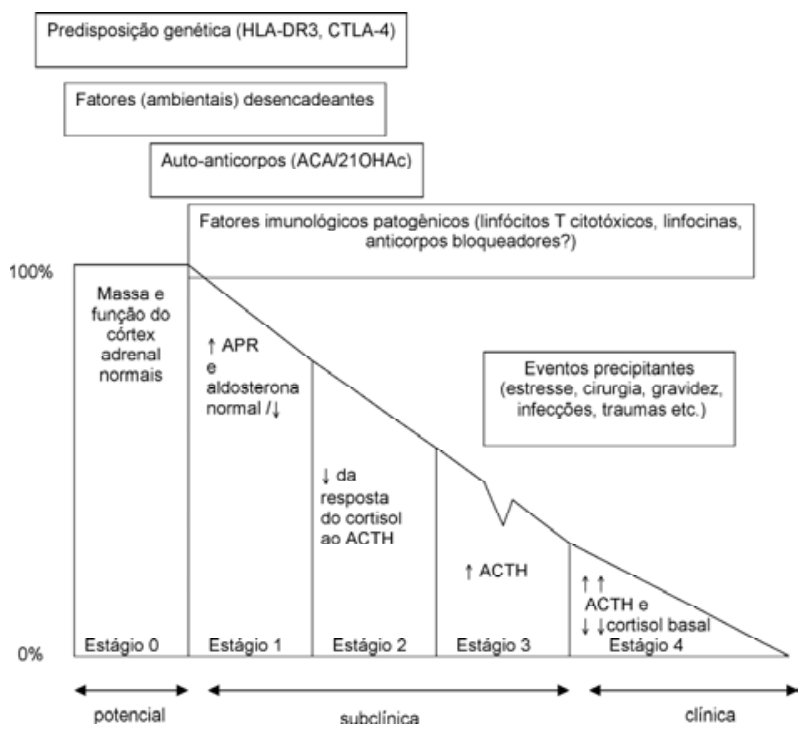

Figura 2. História natural da insuficiência adrenal primária de etiologia auto-imune (referência 2 ). 
de hormônios corticosteróides produzidas localmente e/ou maior habilidade de regeneração (10). Remissão dos sinais bioquímicos de disfunção adrenal pode ser observada em até $50 \%$ dos pacientes com DA potencial ou no estágio 1 , associada ao desaparecimento ou negativação dos 210 HAc $(62,69)$.

Após vários meses ou anos, disfunção da zona fasciculada se torna evidente, como mostrado pela diminuição da resposta do cortisol 60 minutos após estímulo rápido com $250 \mu$ ge $\mathrm{ACTH}_{1-24}$ i.v. (estágio 2) e, posteriormente, pelo aumento dos níveis plasmáticos de ACTH (estágio 3) (10). Existe correlação entre os valores de $210 \mathrm{HAc}$ e o grau de disfunção adrenal em indivíduos com insuficiência adrenal préclínica, de forma que os estágios 2 e 3 coincidem com a síntese de altos níveis de 210 HAc e a ativação de uma fase destrutiva irreversível do processo autoimune (62). Nesta fase, situações que necessitem de aumento da secreção de cortisol (traumas, infecções, cirurgias, gravidez ou outros eventos relacionados ao estresse) podem facilmente precipitar falência adrenocortical (10). Finalmente, a progressão da doença resulta em diminuição evidente dos valores basais de cortisol associada a um grande aumento dos valores de ACTH, juntamente com a presença dos sintomas de insuficiência adrenocortical (estágio 4) (10,68).

Cabe salientar que a insuficiência adrenal primária auto-imune pode acompanhar a doença autoimune tireoideana. Avaliando 65 pacientes com doença de Graves e 47 pacientes com tireoidite de Hashimoto no serviço de Endocrinologia da UNIFE$\mathrm{SP}$, detectamos a presença de $210 \mathrm{OHAc}$ em $3 \%$ e $2 \%$ dos casos, respectivamente. A atividade plasmática da renina, em posição ortostática, estava elevada em todos os pacientes positivos para 210HAc na presença de níveis normais de aldosterona, cortisol e ACTH, assim como a resposta do cortisol após estímulo rápido com 250ug de $\mathrm{ACTH}_{1-24}$ (65).

\section{DOENÇA DE ADDISON DE CAUSA INFECCIOSA}

No Brasil, outra causa importante de DA é a paracoccidioidomicose, micose sistêmica, mais comum na América Latina, causada pelo fungo dimórfico Paracoccidioides brasilensis, que afeta predominantemente homens com mais de 30 anos, habitantes de áreas rurais. $\mathrm{O}$ acometimento adrenal, em achados de necrópsia, ocorre em $50 \%$ a $80 \%$ dos casos (70). Hipofunção do córtex adrenal é freqüente na paracoccidioidomicose disseminada ( $14 \%$ a $44 \%$ dos casos) e DA sintomática ocorre em $5 \%$ a $14 \%$ dos casos (71-73).
Outras infecções fúngicas sistêmicas que podem levar à falência adrenocortical são a histoplasmose, a criptococose e a coccidioidomicose (71). Em estudo relatado pelo nosso grupo na FMRP-USP (74), verificou-se a ocorrência de DA em 10,6\% de pacientes com paracoccidioidomicose, caracterizada pela elevação dos valores basais de ACTH e baixas concentrações de cortisol após estímulo com ACTH [1-24]. Ainda no referido estudo, observou-se, também, o aumento da atividade de renina plasmática $(31 \%)$, redução da aldosterona plasmática (23\%) e redução das concentrações plasmáticas de SDHEA (50\%). Relatamos, em outro estudo, a correlação inversa entre SDHEA e interleucina- 6 em pacientes com paracoccidioidomicose, sugerindo uma interação entre as citocinas inflamatórias e a secreção de andrógenos adrenais em estados inflamatórios crônicos (75). Observamos que alguns pacientes com paracoccidioidomicose, sem sintomas clínicos de insuficiência adrenal, podem apresentar alteração da função da zona glomerulosa com preservação da zona fasciculada. Como não há uma destruição predominante da zona glomerulosa na DA secundária à paracoccidioidomicose (76), sugerimos que possa existir uma adaptação na função adrenal, na tentativa de produzir preferencialmente glicocorticóide no indivíduo com uma doença sistêmica. Portanto, a evolução da DA, tanto de etiologia autoimune como secundária à paracoccidioidomicose, apresenta história natural semelhante (figura 2).

A tuberculose é uma infecção bacteriana comum em nosso meio e, na forma disseminada, também pode comprometer as adrenais, embora com menor freqüência que a paracoccidioidomicose. Dezessete a $20 \%$ dos casos de DA são secundários à tuberculose (77). O trofismo pela adrenal é decorrente da supressão da imunidade celular na adrenal, determinada pela elevada concentração intraglandular de glicocorticóides (20 a 40 vezes maior que na circulação periférica) (78). Do ponto de vista anátomopatológico, na tuberculose ativa, as adrenais estão aumentadas (assim como nas micoses sistêmicas) e apresentam massa caseosa. Posteriormente, as glândulas atrofiam, podendo apresentar calcificações. Punçãobiópsia de massas adrenais, guiada por tomografia computadorizada ou ultra-som, permite a análise histopatológica do tecido adrenocortical e, portanto, a descrição da etiologia específica da DA. Na prática clínica, a punção biópsia de adrenal ainda é pouco realizada, por ser um procedimento invasivo (71).

Uma outra causa de DA é a síndrome de imunodeficiência humana adquirida (SIDA), na qual a adrenal é destruída por agentes causadores de 
infecções oportunistas (Citomegalovírus, Mycobacteri um avium-intracelulare, Cryptococcus neoformans, bactérias e protozoários) ou por sarcoma de Kaposi, em até $5 \%$ dos pacientes nos estágios tardios da doença. Dezoito por cento dos pacientes com SIDA apresentam hipofunção do córtex adrenal e, à necrópsia, necrose adrenocortical extensa (79).

\section{DOENCA DE ADDISON CAUSADA POR INFILTRAÇĀO NEOPLÁSICA}

Metástases para a glândula adrenal são comuns, ocorrendo em até $70 \%$ dos pacientes com câncer de pulmão ou mama disseminados, pois a adrenal é muito vascularizada. Linfomas, melanomas e metástase de carcinoma de rim, estômago e cólon também podem acometer as adrenais. No entanto, insuficiência adrenocortical é pouco freqüente, exceto nos casos de destruição adrenal bilateral (71).

\section{ADRENOLEUCODISTROFIA E ADRENOMIELONEUROPATIA}

A adrenoleucodistrofia e a adrenomieloneuropatia são doenças de herança recessiva ligada ao $\mathrm{X}$, causadas por mutação no gene ALD (Xq28). A produção de uma proteína transportadora peroxissomal anormal impede a oxidação dos ácidos graxos de cadeia muito longa, levando ao seu acúmulo na substância branca cerebral e no córtex adrenal, com conseqüente desmielinização do sistema nervoso e insuficiência adrenocortical primária $(12,13)$. De acordo com a idade de aparecimento e fenótipo clínico, a ALD pode ser classificada em quatro diferentes formas (80): ALD da criança, cujo quadro neurológico se manifesta antes dos 10 anos de idade, evolui progressiva e rapidamente para o estado vegetativo, tendo evolução fatal em tempo variável; ALD do adolescente manifesta-se entre 10 e 21 anos de idade com quadro neurológico de evolução mais lenta; adrenomieloneuropatia caracterizada pelo seu início na vida adulta acometendo principalmente a medula espinhal e nervos periféricos; e ALD do adulto, que pode ocorrer em $20 \%$ de pacientes heterozigotos do sexo feminino, manifestando-se com ataxia e doença medular progressiva. Alguns pacientes podem apresentar insuficiência adrenal ou doença neurológica isoladamente.

O quadro clínico da ALD caracteriza-se pela doença neurológica progressiva, com paraplegia espástica, neuropatia periférica, ataxia, dificuldade na fala, cegueira, perda da audição. Adicionalmente, está associada com insuficiência adrenal primária com hiperpigmentação da pele e mucosas e hipogonadismo hipergonadotrófico. O estudo patológico da adrenal, testículos e do sistema nervoso é caracterizado pelo acúmulo de lipídios. A adrenomieloneuropatia acomete homens jovens, os quais apresentam paralisia espástica, DA e falência gonadal. A DA está presente em $30 \%$ dos pacientes com adrenoleucodistrofia e envolvimento cerebral, em $40 \%$ daqueles com adrenomieloneuropatia e pode ser a única manifestação da doença em até $8 \%$ dos casos $(12,13,81,82)$. Em $80 \%$ a $90 \%$ dos casos, os sinais endócrinos precedem os sintomas neurológicos $(81,82)$. Portanto, a possibilidade de ALD deve ser suspeitada em meninos com doença de Addison, mesmo na ausência de demência ou distúrbio neurológico progressivo (83).

A alteração metabólica da ALD caracteriza-se pelas concentrações elevadas de ácidos graxos de cadeia muito longa (AGCML) no plasma e nos tecidos devido à redução da atividade da acil-CoA sintetase de cadeia muito longa peroxissomal (80). O diagnóstico é confirmado pelas altas concentrações plasmáticas de AGCML, principalmente os ácidos tetracosanóico (C24:0) e hexacosanóico (C26:0), e por alterações radiológicas típicas com grandes áreas simétricas de desmielinização parieto-occipital (80).

\section{MANIFESTAÇŌES CLÍNICAS DA DOENÇA DE ADDISON}

As manifestações clínicas da insuficiência adrenal crônica podem ser inespecíficas, ocasionando o retardo no diagnóstico da doença. Muitas vezes a doença é insidiosa e o diagnóstico é freqüentemente suspeitado durante uma crise de insuficiência adrenal aguda, decorrente de alguma intercorrência, como infecção ou trauma. Os principais sintomas incluem fadiga, fraqueza, anorexia, perda de peso, tontura, náusea e vômito. Entre as manifestações mais específicas da falência adrenal, observamos a presença de hiperpigmentação cutânea ocasionada pela elevação das concentrações plasmáticas de ACTH, que apresenta afinidade pelo receptor $\mathrm{MCl}$ na pele. Tipicamente, esta pigmentação pode ser observada nas áreas expostas ao sol, nos pontos de pressão, dobras cutâneas, palmas das mãos, genitália, cicatrizes recentes e mucosa oral. Muitas vezes, a pigmentação cutânea pode preceder o aparecimento de outras manifestações clínicas de insuficiência adrenal primária, pois numa fase inicial da doença, a reserva adrenal ainda é 
suficiente, isto é, as concentrações plasmáticas de cortisol podem ser mantidas às custas da elevação de ACTH. A tabela 3 apresenta as manifestações clínicas de pacientes com DA diagnosticados e acompanhados na Divisão de Endocrinologia da FMRP-USP.

A deficiência de mineralocorticóide resulta em desidratação, hipovolemia, hipotensão postural, hiponatremia e hipercalemia. Como manifestação clínica, o paciente pode apresentar avidez por sal. A falência adrenocortical inclui a zona reticularis, levando à deficiência de andrógenos na mulher. Portanto, a mulher com insuficiência adrenal apresenta, freqüentemente, perda dos pêlos axilares e pubianos e redução da libido.

\section{DIAGNÓSTICO DA DOENÇA DE ADDISON}

A inespecificidade dos sintomas e sinais da insuficiência adrenal crônica muitas vezes retarda o diagnóstico da DA. A investigação da insuficiência adrenal inclui a realização de exames laboratoriais de rotina e de testes específicos, como a dosagem de ACTH, atividade plasmática de renina (ARP) e estímulo com $\mathrm{ACTH}_{1-24}$ (84). A tabela 4 apresenta os achados laboratoriais de pacientes com DA acompanhados no FMRP-USP. Hiponatremia $(131 \pm 10 \mathrm{mEq} / 1)$ e hipercalemia $(6 \pm$ $1,5 \mathrm{mEq} / \mathrm{l})$ estão presentes na maioria dos pacientes com DA e, muitas vezes, a realização destes exames de rotina conduz à suspeita clínica inicial de insuficiência adrenal. As determinações de cortisol e ACTH basais são úteis na investigação da reserva adrenal, pois seus valores dentro dos limites de referência podem confirmar a função normal. Por outro lado, os valores baixos de cortisol na presença de valores indetectáveis de ACTH ou menores que $20 \mathrm{pg} / \mathrm{ml}$ são consistentes

Tabela 3. Manifestações clínicas e laboratoriais observadas em 44 pacientes com insuficiência adrenal primária (HC FMRP-USP).

\begin{tabular}{lc}
\hline MANIFESTAÇĀO CLíNICA & $\%$ \\
\hline Hiperpigmentação muco-cutânea & 80 \\
Perda de peso & 78 \\
Fraqueza/astenia/fadiga & 74 \\
Vômito & 65 \\
Náusea & 61 \\
Anorexia & 61 \\
Tontura & 56,5 \\
Diminuição da libido / & 46 \\
Rarefação de pelos na mulher & 46 \\
Hipotensão postural & 30 \\
Avidez por sal & 8,7 \\
Diarréia & 6,5 \\
Achado Laboratorial: & 79,5 \\
Hipercalemia & 68 \\
Hiponatremia & \\
\hline
\end{tabular}

Arq Bras Endocrinol Metab vol $48 n^{\circ} 5$ Outubro 2004 com o diagnóstico de insuficiência adrenal secundária. Concentrações de cortisol plasmático $(<5 \mu \mathrm{g} / \mathrm{dl})$ ou de suas formas livres (cortisol urinário ou salivar) baixas e concentrações elevadas de ACTH (> $100 \mathrm{pg} / \mathrm{ml}$ ) confirmam a presença de insuficiência adrenal primária. Observamos em nossa série que muitos pacientes apresentam valores de cortisol indetectáveis, estando a média abaixo do limite inferior da faixa de referência $(2,7 \pm 2,6 \mu \mathrm{g} / \mathrm{dl})$ e com valores de ACTH elevados com média de $866 \pm 1021 \mathrm{pg} / \mathrm{ml}$. No entanto, em muitos pacientes há necessidade de realização de teste de estímulo com ACTH, pois os valores basais de cortisol e ACTH não permitem a definição da reserva adrenal.

O teste do ACTH exógeno (injeção endovenosa de $250 \mu \mathrm{g}$ de $\mathrm{ACTH}_{1-24}$ ) tem se tornado o principal teste para diagnóstico de insuficiência adrenal primária. Resposta do cortisol acima de $19 \mu \mathrm{g} / \mathrm{dl}$ após estímulo com ACTH exógeno indica reserva adrenal preservada. A realização destes testes não é factível na sala de urgência, portanto, na suspeita de crise addisoniana, recomenda-se a coleta de sangue para determinação imediata de sódio, potássio, e armazenamento de plasma para posterior dosagem de ACTH e cortisol, seguida da administração imediata de glicocorticóide, em casos de risco de vida.

Cabe ressaltar que a dose de $250 \mu \mathrm{g}$ de $\mathrm{ACTH}_{1-24}$ utilizada no teste clássico é suprafisiológica e que, recentemente, a utilização do teste com doses mais baixas de $\mathrm{ACTH}_{1-24}$ tem sido relatada, principalmente para o diagnóstico de uma fase mais precoce da DA (85). Laureti e cols. (86) demonstraram que $1 \mu \mathrm{g}$ de $\mathrm{ACTH}_{1-24}$ apresenta alta sensibilidade e especificidade diagnósticas para a insuficiência adrenocortical primária (resposta subnormal do cortisol em $45 \%$ dos pacientes positivos para $210 \mathrm{OHAc}$ e ACA-IFI), sendo útil para a identificação de pacientes com disfunção adrenal pré-clínica $(66,86)$. Doses de $\mathrm{ACTH}_{1-24}$ menores que $\mathrm{l} \mu \mathrm{g}$ têm sido consideradas para avaliação da função adrenal. A identificação de indivíduos com disfunção adrenal pré-clínica foi relatada, utilizandose a dose de $\mathrm{ACTH}_{1-24}$ de 0,06ug, dose esta capaz de estimular a secreção adrenal em indivíduos jovens normais. Giordano e cols. (66) avaliaram pacientes com doenças auto-imunes não adrenais, os quais apresentavam resposta normal do cortisol no teste com 250 $\mathrm{g}$ de $\mathrm{ACTH}_{1-24}$, mas perda da resposta (inclusive de aldosterona e DHEA) no teste com doses muito baixas de $\mathrm{ACTH}_{1-24}(0,06 \mu \mathrm{g})$. Portanto, uma sensibilidade reduzida ao ACTH em todas as zonas adrenocorticais ocorre em pacientes com diferentes tipos de doenças auto-imunes, possibilitando o diagnóstico da fase subclínica da DA (66).

A determinação de autoanticorpos adrenais, quando disponível, pode ser usada na prática clínica 
Tabela 4. Achados laboratoriais observados em 44 pacientes com insuficiência adrenal primária (FMRP-USP).

\begin{tabular}{lcc}
\hline & Insuficiência Adrenal Primária Valores de Referência \\
\hline Cortisol Basal $(-\mu \mathrm{g} / \mathrm{dl})$ & $2,7 \pm 2,6$ & $5-20$ \\
Cortisol $60 \mathrm{~min}$ pós ACTH & $5,3 \pm 5,3$ & $30 \pm 1,5$ \\
$(\mu \mathrm{g} / \mathrm{dl})$ & $866 \pm 1021$ & $10-50$ \\
$\mathrm{ACTH}(\mathrm{pg} / \mathrm{ml})$ & $15,5 \pm 15$ & Feminino: $80-300$ \\
SDHEA $(\mu \mathrm{g} / \mathrm{dl})$ & $21,7 \pm 20,3$ & Masculino: $250-350$ \\
& $9,9 \pm 9$ & $1,24 \pm 1,09$ \\
ARP* $\left(\mathrm{ng} / \mathrm{ml}^{\prime} \mathrm{h}\right)$ & $131 \pm 10$ & $1-16$ \\
Aldosterona* $(\mathrm{ng} / \mathrm{dl})$ & $6 \pm 1,5$ & $136-145$ \\
Sódio $(\mathrm{mEq} / \mathrm{l})$ & $76,6 \pm 23,4$ & $3,5-4,5$ \\
Potássio $(\mathrm{mEq} / \mathrm{l})$ & & $70-110$ \\
Glicose $(\mathrm{mg} / \mathrm{dl})$ &
\end{tabular}

ARP: atividade plasmática de renina

* Em decúbito dorsal e sob dieta normossódica

para discriminação das causas auto-imunes das outras causas de insuficiência adrenal primária. Dada a alta sensibilidade e especificidade dos ensaios utilizados na determinação de autoanticorpos adrenais, alguns autores preconizam este teste como um dos primeiros a ser realizados na classificação etiológica da DA (9).

Nos meninos e homens com insuficiência adrenal primária isolada, sem evidências de adrenalite auto-imune ou testes sorológicos negativos para micoses profundas, deve-se realizar a determinação de ácidos graxos de cadeia muito longa (C26, C26/C22 e C24/C22) para investigação de adrenoleucodistrofia ou adrenomieloneuropatia (87).

Recentemente, o avanço dos métodos de imagem (tomografia computadorizada e ressonância magnética) tem permitido a visualização das adrenais, sendo que na adrenalite auto-imune, além da redução do volume glandular bilateral, há uma ausência característica de calcificação (88). O acometimento das glândulas adrenais por doença granulomatosa é evidenciado pelo aumento das mesmas e pela presença de calcificação e necrose caseosa no exame de tomografia computadorizada. Estes achados são característicos de infecção ativa. Com a evolução da doença, pode-se observar atrofia com ou sem calcificação. Os exames de imagem das adrenais também são importantes na investigação de hemorragia e metástases adrenais.

\section{TRATAMENTO DA DOENÇA DE ADDISON}

Nos pacientes com DA clínica estabelecida, a terapia de reposição com glico- e mineralocorticóide é essencial para a manutenção da vida (71). Na ausência de estresse, a maioria dos adultos com insuficiência adrenal era tratada anteriormente com 20 a $30 \mathrm{mg} /$ dia de hidrocortisona ou dose equivalente de outro glicocorticóide (acetato de cortisona, prednisona ou prednisolona) (71). No entanto, foi demonstrado que, na ausência de estresse, a taxa de secreção diária de cortisol é menor $\left(6 \mathrm{mg} / \mathrm{m}^{2}\right.$ de superfície corpórea/dia) que a dose de glicocorticóide utilizada anteriormente $\left(12-15 \mathrm{mg} / \mathrm{m}^{2} \mathrm{de}\right.$ superficie corpórea/dia) (89). Portanto, atualmente, os pacientes com DA são tratados com 15 a $25 \mathrm{mg} /$ dia de hidrocortisona, divididos em duas $(2 / 3$ pela manhã e $1 / 3$ no início da tarde) ou três doses (três frações iguais) (71). No Brasil, como não há disponibilidade comercial de hidrocortisona oral, em situações de dificuldade de manipulação desta droga, pode-se utilizar prednisona (5$10 \mathrm{mg} /$ dia em dose única ou fracionada). A reposição mineralocorticóide disponível é a $9 \delta$ fluorohidrocortisona (nome comercial nos EUA e Europa Florinef ${ }^{\circledR}$ Bristol-Myers Squib), não disponível comercialmente Brasil. A dose de $9 \delta$ fluorohidrocortisona, em geral, é de 0,05 a $0,15 \mathrm{mg}$ por dia.

A administração de preparados androgênicos pode ser indicada, particularmente em mulheres jovens, para a restauração da libido e atividade sexual normais e manutenção adequada da pilificação axilar e pubiana. A administração de $50 \mathrm{mg} /$ dia de dehidroepiandrosterona (DHEA) por via oral em dose única mantém concentrações de DHEA e de seu sulfato (SDHEA) semelhantes às de mulheres normais, melhorando o bem estar geral e a sexualidade dessas pacientes, além de reduzir o risco de osteoporose na pós-menopausa. DHEA tem efeito direto sobre o sistema nervoso central e é transformado em andrógenos potentes em uma variedade de tecidos $(90,91)$.

Todo paciente com DA deve ser orientado quanto ao risco de crise adrenal em vigência de 
infecção, cirurgia ou trauma. Para minimizarmos os riscos de crise adrenal ou demora na introdução de medidas adequadas, todo paciente deve possuir identificação de portador de insuficiência adrenal e de orientação das medidas necessárias em situações de risco. Adicionalmente, em vigência de infecções sem repercussões sistêmicas importantes, o paciente deve ser orientado a aumentar a dose habitual do glicocorticóide em duas ou três vezes, enquanto persistir o quadro de infecção. Em casos de cirurgias eletivas, recomenda-se a utilização de hidrocortisona endovenosa na dose de $100 \mathrm{mg}$ na indução anestésica, seguida de 50 a 100mg de 6/6 horas, com redução progressiva a partir do segundo dia, de acordo com a recuperação do paciente.

\section{PERSPECTIVAS FUTURAS}

Com a possibilidade de detecção dos ACA/21OHAc, que permite a identificação de indivíduos de risco para o desenvolvimento da DA auto-imune, pode-se utilizar, de forma profilática, a terapia substitutiva com glicocorticóides (terapia iso-hormonal) na fase pré-clínica da DA, a fim de reduzir a função das células adrenocorticais e a expressão antigênica, de forma a lentificar ou até mesmo interromper o processo auto-imune, retardando o início clínico da doença. Essa terapia também pode prevenir crise adrenal durante estresse ou infecção. No momento, entretanto, o valor dessa estratégia terapêutica não está bem estabelecido (92). A prevenção de doenças auto-imunes por meio de imunossupressão ou imunomodulação com auto-antígenos é muito atraente. Progressos nos estudos do papel dos linfócitos $\mathrm{T}$ e a identificação dos auto-antígenos reconhecidos pelos seus receptores poderão levar, no futuro, ao desenvolvimento de uma vacina efetiva (10). Reversibilidade da disfunção adrenal auto-imune também pode ser induzida por corticoterapia em dose imunossupressora, apesar de títulos elevados de ACA (1:32 a 1:64), mesmo em pacientes em estágios mais avançados da insuficiência adrenocortical subclínica (69). Deve-se ressaltar que o tratamento imunossupressor da doença adrenal auto-imune ainda não está bem estabelecido, não sendo indicado, portanto, como tratamento de rotina desta doença.

\section{REFERÊNCIAS}

1. Addison T. On the constitutional and local effects of disease of the supra-renal capsules. Med Classics 1937;2:244-93.

2. Thorn $\mathrm{GW}$. The diagnosis and treatment of adrenal insufficiency. Charles C. Thomas Publisher; 1951.

3. Medvei VC. The history of clinical endocrinology. The Pathernon Publishing Group; 1993.

4. Stuart-Mason A, Meade TW, Lee JAH, Morris JN. Epidemiological and clinical picture of Addison's disease. Lancet 1968;2:744-7.

5. Nerup J. Addison's disease - a review of some clinical, pathological and immunological features. Dan Med Bull 1974;21:201-17.

6. Kong MF, Jeffcoat W. Eighty-six cases of Addison's disease. Clin Endocrinol 1994;41:757-61.

7. Willis AC, Vince FP. The prevalence of Addison's disease in Coventry, UK. Postgrad Med J 1997;73:286-8.

8. Laureti S, Vecchi L, Santeusanio F, Falorni A. Is the prevalence of Addison's disease underestimated? J Clin Endocrinol Metab 1999;84:1762.

9. Falorni $A$, Laureti $S$, de Bellis $A$, Zanchetta R, Tiberti C, Arnaldi $G$, et al. Italian Addison network study: update of diagnostic criteria for the etiological classification of primary adrenal insufficiency. J Clin Endocrinol Metab 2004;89:1598-604.

10. Betterle C, Dal Pra C, Mantero F, Zanchetta R. Autoimmune adrenal insufficiency and autoimmune polyendocrine syndromes: autoantibodies, autoantigens and their applicability in diagnosis and disease prediction. End Rev 2002;23:327-64.

11. Tem S, New Maclaren N. Addison's disease 2001. J Clin Endocrinol Metab 2001;86:2909-22.

12. Laureti S, Casucci G, Angeletti $G$, Celleno R, Santeusanio F, Brunetti P. Adrenoleucodistrofia-X-Linked nel morbo di Addison (revisione della letteratura e nostra personale esperienza). Riv Neurobiologia 1996;42:23-30.

13. Elias แK, Castro M. Insuficiência adrenal primária de causa genética. Arq Bras Endocrinol Metab 2002;46:478-89.

14. Nerup J. Addison's disease - clinical studies. A report of 108 cases. Acta Endocrinol (Copenh) 1974;76:127-41.

15. Fujli $\mathrm{Y}$, Kato N, Kito J, Asai J, Yokochi T. Experimental autoimmune adrenalitis: a murine model for Addison's disease. Autoimmunity 1992;12:47-52.

16. Dittmar M, Kahaly GJ. Polyglandular autoimmune syndromes: immunogenetics and long-term follow-up. J Clin Endocrinol Metab 2003;88:2983-92.

17. Brenner $O$. Addison's disease with atrophy of the cortex of suprarenals. Q J Med 1928;22:121-44.

18. Petri M, Nerup J. Addison's adrenalitis. Studies on diffuse lymphocytic adrenalitis (idiopathic Addison's disease) and focal lymphocytic infiltration in a control material. Acta Pathol Microbiol Scand 1971;79:381-8. 
19. Hayashi Y, Hioshi T, Takemura T, Kurashima C, Hirokawa $K$. Focal lymphocytic infiltration in the adrenal cortex in the elderly: immunohistological analysis of infiltrating lymphocytes. Clin Exp Immunol 1989;77:101-5.

20. Nerup J, Andersen V, Bendixen G. Anti-adrenal cellular hypersensitivity in Addison's disease. Clin Exp Immunol 1969;4:355-63.

21. Fairchild RS, Schimke RN, Abdou NI. Immunoregulation abnormalities in familial Addison's disease. J Clin Endocrinol Metab 1980;51:1074-7.

22. Rabinowe SL, Jackson RA, Dluhy RG, Williams GH. lapositive T lymphocytes in recently diagnosed idiopathic Addison's disease. Am J Med 1984;77:597-601.

23. Freeman M, Weetman AP. T and B cell reactivity to adrenal antigens in autoimmune Addison's disease. Clin Exp Immunol 1992;88:275-9.

24. Betterle C, Volpato M, Greggio NA, Presotto F. Type 2 polyglandular autoimmune disease (Schmidt's syndrome). J Pediatr Endocrinol Metab 1996;9:1 13-23.

25. Betterle $C$, Volpato $M$. Adrenal and ovarian autoimmunity. Eur J Endocrinol 1998; 138:16-25.

26. Huang W, Connor E, Rosa TD, Muir A, Schatz D, Silverstein J, et al. Although DR3-DQB1 ${ }^{*} 0201$ may be associated with multiple component diseases of the autoimmune polyglandular syndromes, the human leucocyte antigen DR4$\mathrm{DQB} 1{ }^{*} 0302$ haplotype is implicated only in B-cell autoimmunity. J Clin Endocrinol Metab 1996;81:2559-63.

27. Yu L, Brewer KL, Gates S, Wu A, Wang T, Babu SR, et al. $D R B 1{ }^{*} 04$ and $D Q$ alleles: expression of 21 -hydroxylase autoantibodies and risk of progression to Addison's disease. J Clin Endocrinol Metab 1999;84:328-35.

28. Myhre AG, Undlien DE, Lovas $K$, Uhlving S, Nedrebo BG, Fougner KJ, et al. Autoimmune adrenocortical failure in Norway. Autoantibodies and human leukocyte antigen class II associations related to clinical features. J Clin Endocrinol Metab 2002;87:618-23.

29. Partanen J, Peterson P, Westman P, Aranko S, Krohn K. Major histocompatibility complex class II and III in Addison's disease. MHC alleles do not predict autoantibody specificity and 21 -hydroxylase gene polymorphism has no independent role in disease susceptibility. Hum Immunol 1994;41:135-40.

30. Peterson P, Partanen J, Aavik E, Salmi H, Pelkonen R, Krohn KJE. Steroid 21-hydroxylase gene polymorphism in Addison's disease patients. Tissue Antigens 1995;46:63-7.

31. Gambelunghe G, Falorni A, Ghaderi M, Laureti S, Tortoioli C, Santeusanio F, et al. Microsatellite polymorphism of the MHC class I chain-related (MIC-A and MICB) genes marks the risk for autoimmune Addison's disease. J Clin Endocrinol Metab 1999;84:3701-7.

32. Donner H, Braun J, Seidl C, Rau H, Finke R, Ventz M, et al. Codon 17 polymorphism of the cytotoxic T lymphocyte antigen 4 gene in Hashimoto's thyroiditis and Addison's disese. J Clin Endocrinol Metab 1997;82:4130-2.

33. Kemp EH, Aijan RA, Husebye ES, Peterson P, Uibo R, Imrie $\mathrm{H}$, et al. A cytotoxic T lymphcyte antigen-4 (CTLA-4) gene polymorphism is associated with autoimmune Addison's disease in English patients. Clin Endocrinol 1998;49:609-13.
34. Anderson JR, Goudie RB, Gray KG, Timbury GC. Autoantibodies in Addison's disease. Lancet 1957;1:1 123-4.

35. Nerup J. Addison's disease - serological studies. Acta Endocrinol 1974;76:142-58.

36. Silva RC, Faiçal S, Laureti S, Falorni A, Dib AS, Kater CE. Detection of adrenocortical autoantibodies in Addison's disease with a peroxidase-labelled protein A technique. Braz J Med Biol Res 1998;31:1141-8.

37. Khoury EL, Hammond L, Bottazzo GF, Doniach D. Surface-reactive antibodies to human adrenal cells in Addison's disease. Clin Exp Immunol 1981;45:48-55.

38. Winqvist $O$, Anders Karlsson F, Kämpe O. 21-hydroxylase, a major autoantigen in idiopathic Addison's disease. Lancet 1992;339:1559-62.

39. Falorni A, Nikoshkov A, Laureti S, Grenbäck E, Hulting AL, Casucci $G$, et al. High diagnostic accuracy for idiopathic Addison's disease with a sensitive radiobinding assay for autoantibodies against recombinant human 21-hydroxylase. J Clin Endocrinol Metab 1995;80:2752-5.

40. do Carmo Silva R, Kater CE, Atala Dib S, Laureti S, Forini $\mathrm{F}$, Cosentino A, et al. Autoantibodies against recombinant human steroidogenic enzymes 21-hydroxylase, side chain cleavage and 17a-hydroxylase in Addison's disease and autoimmune polyendocrine syndrome type III. Eur J Endocrinol 2000; 142:187-94.

41. Betterle C, Volpato M, Pedini B, Chen S, Smith BR, Furmaniak J. Adrenal-cortex autoantibodies and steroidproducing cells autoantibodies in patients with Addison's disease: comparison of immunoflorescence and immunoprecipitaion assays. J Clin Endocrinol Metab 1999;84:618-22.

42. Wedlock N, Asawa T, Baumann-Antczak A, Rees Smith B, Furmaniak J. Autoimmune Addison's disease. Analysis of autoantibody binding sites on human steroid 21hydroxylase. FEBS Lett 1993;332:123-6.

43. Song YH, Connor EL, Muir A, She JX, Zorovich B, Derovanesian $D$, et al. Autoantibody epitope mapping of the 21-hydroxylase antigen in autoimmune Addison's disease. J Clin Endocrinol Metab 1994;78:1108-12.

44. Chen S, Sawicka J, Prentice L, Sanders JF, Tanaka H, Petersen V, et al. Analysis of autoantibody epitopes on steroid 21-hydroxylase using a panel of monoclonal antibodies. J Clin Endocrinol Metab 1998;83:2977-86.

45. Nikoshkov A, Falorni A, Lajic S, Laureti S, Wedell A, Lernmark $A$, et al. A conformational-dependent epitope in Addison's disease and other endocrinological autoimmune diseases maps to a carboxyl-terminal functional domain of human steroid 21-hydroxylase. J Immunol 1999:162:2422-6.

46. Volpato M, Prentice L, Chen S, Betterle C, Rees Smith B, Furmaniak J. A study of the epitopes on steroid 21hydroxylase recognized by autoantibodies in patients with or without Addison's disease. Clin Exp Immunol 1998; 111:422-8.

47. Silva RC, Kater CE. Doença de Addison de etiologia auto-imune. Arq Bras Endocrinol Metab 1998;42:431-3.

48. Irvine WJ, Chan MMW, Scarth L. The further characterization of autoantibodies reactive with extra-adrenal steroid-producing cells in patients with adrenal disorders. Clin Exp Immunol 1969;4:489-503. 
49. Krohn K, Uibo R, Aavik E, Peterson P, Savilahti K. Identification by molecular cloning of an autoantigen associated with Addison's disease as steroid $17 \delta$ hydroxylase. Lancet 1992;339:770-3.

50. Winqvist O, Gustafsson J, Rorsman F, Anders Karlsson F, Kämpe O. Two different cytochrome P450 enzymes are the adrenal antigens in autoimmune polyendocrine syndrome type I and Addison's disease. J Clin Invest 1993; $92: 2377-85$.

51. Chen S, Sawicka J, Betterle C, Powell M, Prentice L, Volpato $M$, et al. Autoantibodies to steroidogenic enzymes in autoimmune polyglandular syndrome, Addison's disease, and premature ovarian failure. J Clin Endocrinol Metab 1996;81:1871-6.

52. Elder M, Maclaren N, Riley W. Gonadal autoantibodies in patients with hypogonadism and/or Addison's disease. J Clin Endocrinol Metab 1981;52:1137-42.

53. Ahonen $P$, Miettinen A, Perheentupa J. Adrenal and steroidal cell antibodies in patients with autoimmune polyglandular disease type I and risk of adrenocortical and ovarian failure. J Clin Endocrinol Metab 1987;64:494-500.

54. Arif S, Vallian S, Farzaneh F, Zanone MM, James SL, Pietropaolo $\mathrm{M}$, et al. Identification of 3b-hydroxysteroid dehydrogenase as a novel target of steroid cell autoantibodies: association of autoantibodies with endocrine autoimmune disease. J Clin Endocrinol Metab 1996;81:4439-45.

55. Winqvist O, Gebre-Medhin G, Gustafsson J, Rítzen EM, Lundkvist Ö, Anders Karlsson F, et al. Identification of the main gonadal autoantigens in patients with adrenal insufficiency and associated ovarian failure. J Clin Endocrinol Metab 1995;80:1717-23.

56. Seissler J, Schott M, Steinbrenner H, Peterson $P$, Scherbaum WA. Autoantibodies to adrenal cytochrome P450 antigens in isolated Addison's disease and autoimmune polyendocrine syndrome type II. Exp Clin Endocrinol Diab 1999;107:208-13.

57. Kendall-Taylor P, Lambert A, Mitchell R, Robertson WR. Antibody that blocks stimulation of cortisol secretion by adrenocorticotrophic hormone in Addison's disease. Br Med J 1988;296:1489-91.

58. Wulffraat NM, Drexhage HA, Bottazzo GF, Wiersinga WM, Jeucken P, van der Gaag R. Immunoglobulins of patients with idiopathic Addison's disease block the in vitro action of adrenocorticotropin. J Clin Endocrinol Metab 1989;69:231-8.

59. Wardle CA, Weetman AP, Mitchell R, Peers N, Robertson WR. Adrenocorticotropic hormone receptor-blocking immunoglobulins in serum from patients with Addison's disease: a reexamination. J Clin Endocrinol Metab 1993;77:750-3.

60. Jackson R, McNicol AM, Farquharson M, Foulis AK. Class II MHC expression in normal adrenal cortex and cortical cells in autoimmune Addiosn's disease. J Pathol 1988; 155: $113-20$.

61. Boscaro M, Betterle C, Volpato M, Fallo F, Furmaniak J, Rees Smith B, et al. Hormonal responses during various phases of autoimmune adrenal failure: no evidence for 21-hydroxylase enzyme activity inhibition in vivo. J Clin Endocrinol Metab 1996;81:2801-4.
62. Laureti S, de Bellis A, Muccitelli VI, Calcinaro F, Bizzarro $A$, Rossi R, et al. Levels of adrenocortical autoantibodies correlate with the degree of adrenal dysfunction in subjects with pre-clinical Addison's disease. J Clin Endocrinol Metab 1998;83:3507-11.

63. Peterson P, Salmi H, Hyöty H, Miettinen A, llonen J, Reijonen $\mathrm{H}$, et al. Steroid 21-hydroxylase autoantibodies in insulin-dependent diabetes mellitus. Clin Immunol Immunopathol 1997;82:37-42.

64. Falorni A, Laureti S, Nikoshkov A, Picchio ML, Hallengren $B$, Vandewalles $C L$, et al. 21-hydroxylase autoantibodies in adult patients with endocrine autoimmune diseases are highly specific for Addison's disease. Clin Exp Immunol 1997;107:341-6.

65. Silva RC, Sallorenzo C, Kater CE, Dib SA, Falorni A. Autoantibodies against glutamic acid decarboxylase and 21-hydroxylase in Brazilian patients with Type 1 diabetes or autoimmune thyroid diseases. Diab Nutr Metab 2003;16:160-8.

66. Giordano R, Pellegrino M, Oleandri S, Baldi M, Balbo M, Laureti $S$, et al. Adrenal sensitivity to adrenocorticotropin 1-24 is reduced in patients with autoimmune polyglandular syndrome. J Clin Endocrinol Metab 2004;89:67580.

67. Betterle C, Volpato M, Rees Smith B, Furmaniak J, Chen S, Greggio NA, et al. I. Adrenal cortex and steroid 21hydroxylase autoantibodies in adult patients with organspecific autoimmune diseases: markers of low progression to clinical Addison's disease. J Clin Endocrinol Metab 1997,82:932-8.

68. Betterle C, Scalici CL, Presotto F, Pedini B, Moro L, Rigon $\mathrm{F}$, et al. The natural history of adrenal function in autoimmune patients with adrenal autoantibodies. J Endocrinol 1988; 117:467-75.

69. de Bellis A, Falorni A, Laureti S, Perrino S, Cronella C, Forini $F$, et al. Time course of 21-hydroxylase autoantibodies and long term remissison of subclinical autoimmune adrenalitis after corticosteroid therapy: case report. J Clin Endocrinol Metab 2001:86:675-8.

70. Franco M, Montenegro MR, Mendes RP, Marques SA, Dillon NL, Mota NGS. Paracoccidioidomycosis: a recently proposed calssification of its clinical forms. Rev Soc Bras Méd Trop 1987;20:129-32.

71. Silva RC. Insuficiência do córtex supra-renal. In: Coronho V, Petrianu A, Santana EM, Pimenta LG, editors. Tratado de Endocrinologia e Cirurgia Endócrina. $1^{a}$ edicão. Rio de Janeiro: Guanabara Koogan, 2001. p.819-30.

72. Colombo AL, Faiçal S, Kater CE. Systematic evaluation of the adrenocortical function in patients with paracoccidioidomycosis. Mycopathologia 1994; 127:89-93.

73. Oliveira MC, Hoiffman KS, Gonzales PH, Severo LC. Presença de hipocortisolismo clínico-laboratorial em pacientes com paracoccidioidomicose. Arq Bras Endocrinol Metab 1995;39:102-6.

74. Moreira AC, Martinez R, Castro M, Elias LLK. Adrenocortical dysfunction in paracoccidioidomycosis: comparison between plasma B-lipotropin/adrenocorticotropin levels and adrenocortical tests. Clin Endocrinol 1992;36:545-54. 
75. Leal AM, Magalhães PK, Martinez R, Moreira AC. Adrenocortical hormones and interleukin patterns in paracoccidioidomycosis. J Infect Dis 2003; 187:124-7.

76. Franco MF, Montenegro MRG. Anatomia patológica. In: Negro G, Lacaz CS, Fiorillo AM, editores. Paracoccidioidomicose. São Paulo: Sarvier-Edusp, 1982. p. 97-117.

77. Pires AC, Vieira JGH. Avaliação da função adrenal em tuberculosos. Estudo da resposta adrenal ao estímulo rápido com ACTH com dosagens de cortisol sérico. Arq Bras Endocrinol Metab 1981;25:90-4.

78. Frenkel JK. Pathogenesis of infection of the adrenal glands leading to Addison's disease in man: the role of corticoids in adrenal and infection. Ann NY Acad Sci 1990;84:391-440.

79. Lewi DS, Kater CE. Insuficiência adrenocortical em pacientes com síndrome de imunodeficiência adquirida (AIDS). Rev Assoc Med Brasil 1988;34:213-8.

80. Moser HW. Adrenoleukodystrophy: phenotype, genetics, pathogenesis and therapy. Brain 1997;120:1485508 .

81. Laureti S, Casucci G, Santeusanio F, Angeletti G, Auborg $P$, Brunetti P. X-linked adrenoleukodystrophy is a frequent cause of idiopathic Addison's disease in young adult male patients. J Clin Endocrinol Metab 1996;81:470-4.

82. Auborg P. The expanding world of primary adrenal insufficiencies. Eur J Endocrinol 1997;137:10-2.

83. Ronghe MD, Barton J, Jardine PE, Crowne EC, Webster $\mathrm{MH}$, Armitage $\mathrm{M}$, et al. The importance of testing for adrenoleucodystrophy in males with idiopathic Addison's disease. Arch Dis Child 2002;86:185-9.

84. Arlt W, Allolio B. Adrenal insufficiency. Lancet 2003;361:1881-93

85 .Dorin RI, Clifford RQ, Crapo LM. Diagnosis of adrenal insufficiency. Ann Intern Med 2003;139:194-204.
86. Laureti S, Arvat E, Candeloro P, Di Vito L, Ghigo E, Santeusanio F, et al. Low dose $(1 \mu \mathrm{g}) \mathrm{ACTH}$ test in the evaluation of adrenal dysfunction in pre-clinical Addison's diseade. Clin Endocrinol 2000;53:107-15.

87. Laureti S, Auborg P, Calcinaro F, Rocchioccioli F, Casucci $G$, Angeletti $G$, et al. Etiological diagnosis of primary adrenal insufficiency using an original flowchart of immune and biochemical markers. J Clin Endocrinol Metab 1998;83:3163-8.

88. Doppman JL, Gill JR, Nienhuis AW, Earl JM, Long JA. CT findings in Addison's disease. J Comput Assist Tomography 1982;6:757-61.

89. Esteban NV, Loughlin T, Yergey AL, Zawadzki JK, Booth JD, Winterer JC, et al. Daily cortisol production rate in man determined by stable isotope dilution/mass spectrometry. J Clin Endocrinol Metab 1991;72:39-45.

90. Arlt W, Callies F, van Vlijmen JC, Koehler I, Reincke M, Bidlingmaier $M$, et al. Dehydroepiandrosterone replacement in women with adrenal insufficiency. $\mathbf{N}$ Engl J Med 1999;341:1013-20.

91. Stewart PM. The adrenal cortex. In: Larsen PR, Kronenberg HM, Melmed S, Polonsky KS. Williams Textbook of Endocrinology. $10^{\text {th }}$ ed. Philadelphia: Saunders, 2003, Chap. 14, p. 491-551.

92. Schloot N, Eisenbarth GS. Isohormonal therapy of endocrine autoimmunity. Immunol Today 1995;16:28994.

\section{Endereço para correspondência:}

Lucila LK Elias

Departamento de Fisiologia

Faculdade de Medicina de Ribeirão Preto - USP

Avenida dos Bandeirantes 3900

14049-900 Ribeirão Preto, SP

Fax: (16) 633-0017

e-mail: llelias@fmrp.usp.br 